\title{
Digital economy: Conceptual architecture of a digital economic sector ecosystem
}

\author{
Yury M. Akatkin \\ Head of Laboratory of Social-Demographic Statistics \\ Plekhanov Russian University of Economics \\ Address: 36, Stremyanny Lane, Moscow, 117997, Russian Federation \\ E-mail: u.akatkin@semanticpro.org
}

\section{Oleg E. Karpov}

Corresponding Member, Russian Academy of Sciences

General Director of Pirogov National Medical-Surgical Center

Address: 70, Nizhnyaya Pervomaiskaya Street, Moscow, 105203, Russian Federation

E-mail: nmhc@mail.ru

\section{Valery A. Konyavskiy}

Head of Information Security Department

Moscow Institute of Physics and Technology

Address: 1A, Kerchenskaya Street, Moscow, 117303, Russian Federation

E-mail: konyavskiy@gospochta.ru

\section{Elena D. Yasinovskaya}

Senior Researcher, Laboratory of Social-Demographic Statistics

Plekhanov Russian University of Economics

Address: 36, Stremyanny Lane, Moscow, 117997, Russian Federation

E-mail: elena@semanticpro.org

\begin{abstract}
The main objective of digital transformation is to fulfill the needs of a "new digital generation customer" for on-demand delivery, quality and personalization. "Anything as a service" has become the key principle of the digital paradigm. This is about a data-oriented service which relies on sharing information resources (including public ones) and the requirements for interoperability, security and trust. This paper presents the main approaches to digital transformation based on the example of the most innovatively active sectors such as banking and healthcare. We compare the proprietary development of digital services (products) to the building of a digital sector ecosystem aimed at attracting an unlimited number of participants. We defined the purpose of creating an ecosystem that is to provide the population with digital services formed on demand, in real time, in compliance with legislation and regulations, as well as in the context of maximum trust. We emphasize the role of openness for uniting the efforts of the community interested in the development of a digital industry, extension of public-private partnerships and building a competitive environment in order to ensure the rapid growth of available digital services, as well as to improve their quality. Since the knowledge
\end{abstract}


economy is the basis for the digital economy, the authors consider it especially important to form a semantic core which acts as the carrier of knowledge in a digital sector ecosystem. We confirmed the necessity to implement the semantic core by a brief analysis of modern semantic approaches to standardization of information sharing in the above-mentioned industries, such as FIBO, BIAN (banking), HL7 and UMLS (health). The research carried out allowed the authors to design the conceptual architecture of the ecosystem and to suggest several proposals for digital transformation of an industry. The proposals express the necessity of state support for innovation and providing the conditions for the entry of new digital products based on the following principles: accessibility, timeliness, personalization, adaptability and security.

Key words: digitalization, digital economy, digital service, economic sector, ecosystem, conceptual architecture, interoperability, information sharing, semantic integration, semantic core.

Citation: Akatkin Y.M., Karpov O.E., Konyavskiy V.A., Yasinovskaya E.D. (2017) Digital economy: Conceptual architecture of a digital economic sector ecosystem. Business Informatics, no. 4 (42), pp. 17-28. DOI: 10.17323/1998-0663.2017.4.17.28.

\section{Introduction}

$\mathrm{M}$ illennials, the generation born between 1980 and 2000, have grown up and are now involved in the labor market, which substantially changes the average customer's needs. They expect high quality services (products) on demand as well as to use mobile and other innovative technologies to which they are accustomed. When the experts forecast The Fourth Industrial Revolution [1], the current situation in various economic sectors calls for digital transformation as well as their integration into the digital world and digital economy.

Although experts have generally reached a consensus about the goals of digital transformation, the term "digital economy" stays rather ambiguous. It retains a focus on marketing following the market trends set for the benefit of the main players. During the last few years, various reviews and concepts made by global analysts and ICT leaders on digitization of economy and its particular sectors have filled the information landscape. Based on research materials, the Analytical Center for the Government of the Russian Federation has compiled seven definitions of "digital economy" and invited experts to discuss them [2].
However, we consider it more useful to move forward from the exact terminology to making concrete steps towards the development of digital economic sectors and further improvement of public administration.

The public sector should regard digital transformation within the overall complex of measures which is required for successful involvement in the global digital economy. The suggestions on e-government digitalization which the authors proposed in the paper "Towards the digital government in Russia: Integrative approach" [3] remain relevant and should be considered within this complex of measures. We discuss the following issues: providing interoperability (at all levels including semantic); building open platforms which enable collaboration between domain and IT experts; establishing an expert community involving key scientists.

In this paper, we suggest a concept of digital sector ecosystem architecture in order to define the main ways and methods of digital transformation. We have considered potential participants and basic ecosystem elements, realization features (based on banking and healthcare sectors) and the role of the state in the future growth of digital economy. This approach has 
allowed us to work out proposals aimed at providing innovations with state support based on public-private partnership principles and to create optimal conditions for the development of customer-oriented digital services and products.

\section{Current state of digital transformation in some economic sectors}

Using up-to-date technologies, digitalization reshapes the competitive picture and blurs the boundaries between the players of economic sectors. Digital leaders, such as Google, Apple, Facebook and Amazon, promote the digital paradigm and people define its significance in accordance with the expectation level of "new digital generation clients", who get used to permanent service accessibility as well as to immediate service delivery. Therefore, large IT corporations, equipment and software providers primarily focus their efforts on changing the form in which they offer products and services to the customer.

Since clients quickly get accustomed to a high level of digital services, the market offers solutions which meet their needs in a better way, by increasing the availability, providing high usability and convenience together with personalization of services according to the customers' individual characteristics and interests.

Thus, the experts characterize the digital transformation by the following features:

$\checkmark$ orientation to customers (a digital service or a digital product is formed in accordance with customer requests and doesn't depend on the producer's offer);

$\downarrow$ orientation towards mobility and velocity (the principle "here and now": using any device, any communication channel);

$\downarrow$ orientation on data (the acquisition of new data from existing data, analysis and decisionmaking).

This leads to the transformation of a business model towards the individualization of services and products. The principle "anything as a service" appears, in which the service is data-oriented. For instance, many people consider the use of "car-sharing" services on par with the purchase of a car, not to mention Uber-like services, which have become a popular success story of the digital economy.

To meet these high customer expectations, companies must accelerate the digitization of their business processes. They should go beyond simply automating existing processes: "They must reinvent the entire business process, including cutting the number of steps required, reducing the number of documents, developing automated decision making, and dealing with regulatory and fraud issues. Operating models, skills, organizational structures, and roles need to be redesigned to match the reinvented processes. Data models should be adjusted and rebuilt to enable better decisionmaking, performance tracking, and customer insights. Digitization often requires that old wisdom be combined with new skills, for example, by training a merchandising manager to program a pricing algorithm. New roles, such as data scientist and user-experience designer, may be needed" [4].

The banking industry is a significant example of rapid digital development. Deloitte conducted research on the use of new technologies in Russian banks, from which experts chose 11 innovations and divided them into several groups: security ("smart" authentication), analytics (Big Data, personal financial assistants), digital technologies (online wallet, contactless payment, etc.), automation (robots in departments), gamification (games and quests for customers) and P2P-crediting [5].

We should note that leaders in the banking sector pay particular attention to IT development and this causes the establishment of digital factories.

Thus, one of the largest banks in Canada, The Bank of Nova Scotia or Scotiabank recently announced the development of a new Digi- 
tal Factory that will pursue, design and deliver digital innovations and solutions for the Bank's customers with the philosophy of "reinventing how banking serves people".

Deutsche Bank now has its own center for developing digital banking products: The Digital Factory in Frankfurt. Roughly 400 software developers, IT specialists and financial experts from 14 nations are working together to develop digital products using state-of-the-art methods [6].

In November 2016, Deutsche Bank (DB) gave software developers from Germany and abroad the opportunity to create digital solutions for bank clients that go far beyond traditional financial services. This approach ensured the creation of an innovation ecosystem which united three innovation labs where the bank cooperates with start-ups from all over the world, the Digital Factory and DB's new research and development center. The bank provides access to its proprietary development environment via an application programming interface (dbAPI) which allows programmers to test their ideas for digital services of the future [7].

The PSD2 (EU Revised Payment Service Directive) $)^{2}$ also supports the logic of open APIs for the provision of payment services. According to this quite disruptive initiative, European banks are obliged to provide thirdparty providers with access to their customers' accounts through open APIs. This will enable third parties (e.g. application developers) to build financial services on top of the banks' data and infrastructure. On behalf of the client and without the need to make an agreement with the bank, a third party will be able to make payments and display information about transactions in its own applications tailored to the customers' expectations. This is another step towards open banking, which, on the one hand, brings anxiety into the banking market, and on the other - it seems to be a new, strategically important,prospect ${ }^{3}$.

On the other hand, the proprietary approach to the development of digital banking services is quite traditionally applied. For example, in 2011 Russia's Sberbank created the IT company "Sbertech". Currently, about 7000 employees in 16 cities are developing 350 projects for this bank. The largest projects are the "Integrated Front-End System", which is a client service in any place through any channel; the "Platform for Business Development support", a tool for business applications creation and the "Data Factory" for monetization of information about clients and analysis of their behavior [8].

Today Sbertech focuses its projects on the modernization of their own in-house developed banking system. However, the development of open interfaces (Open API) is also said to be one of the future directions. For this reason, Sbertech management points towards the creation of marketplaces or aggregators where "together with their partners they will begin to sell not only financial but also related services such as travel and insurance. This is especially true since the banking ecosystem is growing and there are many developers who want to write their own applications related to banking services" [9]. This shows the desire to follow the principles of openness and to attract a large number of independent IT professionals focused on customer-oriented start-up ideas. This is the approach prescribed by the digital paradigm.

The innovation market in healthcare is one of the most active. Digital transformation in this domain is aimed at identification and prevention of most $(80 / 20)$ life and health hazards due to timely preliminary diagnostics and health monitoring, primary medical consul-

${ }^{1} \mathrm{http} / / /$ digitalfactory.scotiabank.com/ (accessed 19 September 2017)

${ }^{2} \mathrm{https} / /$ /ec.europa.eu/info/law/payment-services-psd-2-directive-eu-2015-2366_en (accessed 19 September 2017)

${ }^{3}$ https://nordeaopenbanking.com/ (accessed 19 September 2017) 
tations and personalized on demand medical services, emergency medical care services initiation and referral to in-depth medical examination in high-tech health care centers [10].

The "Accenture Digital Health Technology Vision 2016" [11] emphasizes that keeping up with changing technology is vital, but it is just as important to evolve the consumer experience, care delivery methods and career development opportunities for the healthcare workforce. It reveals five trends that prove winning in the digital age that depends on people:

1. Intelligent Automation: Do things differently, do different things to new jobs, products and services in healthcare;

2. The Liquid Workforce: Today's digital demands call for highly agile healthcare skillsets;

3. Platform Economy: Ecosystems are the new bedrock of digital healthcare;

4. Predictable Disruption: Digital ecosystems blur healthcare's boundaries in a foreseeable way;

5. Digital Trust: As healthcare data security risks increase, so do opportunities to earn consumer trust [11].

The United Kingdom, which is a digital economy leader, is actively creating an infrastructure to provide innovation solution development by involving a wide range of developers interested in digital field progress.

One example of such projects is the "Digital Catapult" , a platform for technical specialists, creative professionals, business and academic representatives who develop new ideas within corporations and promote their products to the British market and abroad. This allows British "digital" companies to implement innovations faster and with less risk. In this way, the entry of new products and services to the market can be accelerated.
Code4Health ${ }^{5}$ is another initiative. It is a program of NHS England and NHS Digital to support health and care professionals with digital tools and technologies to provide safe, effective, and high quality telecare services.

Code4Health intends to educate and inform all community members (citizens, patients, guardians, health care employees and digital technology specialists) about tele-healthcare, the option to use digital technologies and related tools, knowledge and skills for collaboration in design and implementation of high-quality digital solutions [12].

The project comprises the following parts:

$\diamond$ Platform. Code4Health provides a simulated environment in which you can explore the resources you will find in the emerging open digital health and care ecosystem, learn to code, build apps, discover and create content and test your ideas;

$\diamond$ Learning. Code4Health provides clinicians with an explanation of the technologies they use and with opportunities for coeducation to help in designing new advanced services for rendering medical care;

$\diamond$ Communities. Code4Health brings together people with shared interests in digital healthcare. Communities can involve people with a shared interest in some specific aspect of digital healthcare or involve people chosen geographically.

Hence, based on the above information, in order to facilitate digital transformation, the efforts in three interrelated areas will be fundamental:

1. The reengineering of business processes, technologies and business cultures to provide customers with a service in any place and at any time in the digital format they are accustomed to;

\footnotetext{
${ }^{4}$ https://digital.catapult.org.uk/ (accessed 19 September 2017)

${ }^{5}$ https://code4health.org/ (accessed 19 September 2017)
} 
2. Implementation of innovative technologies either in the industry or in the economy in general, to be present in any digital platform using mobile and Internet of Things (IoT) devices;

3. Creation of an organizational form and normative base for attracting innovation and effective cooperation with developers of digital solutions, applications and devices, in the framework of sectoral state regulation, making it possible to reduce administrative barriers to digital transformation.

Therefore, it is also necessary to solve emerging legal problems in a timely manner and change the existing legislation, both in the industry and in the country's digital economy, while maintaining a reasonable degree of state regulation and providing a sufficient level of state support.

The above overview shows that today's digital leaders use different approaches towards the realization of a system for development and implementation of digital services:

1. To create a proprietary system for the development and the implementation of digital services, as well as to establish a digital services development company and to lead independent activity (in the example of Sbertech). Along with obvious benefits, the following disadvantages stand out in this approach:

$\downarrow$ it is the developer (founder) of a proprietary system who defines what clients want; therefore it is difficult to carry out the requirements of the digital economy to focus on the customer's needs;

$\checkmark$ despite increased competition in the IT community, integration with the industry community is complicated, and it is therefore difficult to achieve the proper quality and timeliness of digital services development;

- substantial investments in the creation of specific products and services which may become outdated before the end of the development process.
2 . To create a digital sector ecosystem by consolidating the efforts of digital technology and the application developer community, industry enterprises (for example, in healthcare - medical institutions providing digital healthcare as well as other stakeholders) In our opinion this approach is preferable and is outlined in more detail below.

Current practice shows that digital transformation requires openness and involvement of a wide range of developers who are ready to create innovative digital services. Therefore, the second approach is the most promising. Along with the relevance of this approach for digital transformation, it is important to consider it in more detail.

\section{Digital sector ecosystem}

Experts and consultants [13, 14] have long said that the digital economy is becoming one of the key contributors to GDP growth. It also has important implications for GDP measurement, productivity and household welfare in the retail sector and in all service sectors of the economy [15].

This year the challenges of the digital economy became one of the main themes at the St. Petersburg Economic Forum. It was emphasized that Russia needs to build up human, intellectual and technological advantages in the digital economy sector, and intends to act in directions which have systemic importance. This necessitates the formation of a principally new, flexible normative base to introduce technology in all areas of life ${ }^{6}$. At the same time, all decisions should consider the information security of the state, businesses and citizens ${ }^{7}$.

The following stakeholders should support digital transformation:

- the state - from the standpoint of sectoral regulation, setting norms and rules, providing support measures, as well as encouraging

\footnotetext{
${ }^{6} \mathrm{https}: / /$ sputniknews.com/business/201706021054244434-russia-economy-putin- spief-2017/ (accessed 19 September 2017)

${ }^{7}$ https://ria.ru/economy/20170602/1495725962.html (accessed 19 September 2017)
} 
industry leaders to migrate to a digital paradigm;

- leading enterprises of economic sectors within the framework of consolidating the efforts of expert communities, sharing information resources and providing access to them for the development of digital services, standardization and ensuring a sufficient level of trust and security.

- innovative companies - as the main driver for the emergence of new customer-oriented digital services and products.

In conclusion, the principles of openness and the union of the community's efforts are fundamentally important for digitalization, and the formation of digital economic sector ecosystems becomes the basic solution for the digital economy as a whole.

A digital sector ecosystem is an environment that serves innovative development and the expansion of digital services and products, applications and devices in a particular sector of the digital economy.

The purpose of creating an ecosystem is to provide the population with the digital services formed on demand, in real time, in compliance with legislation and regulations, as well as in the context of maximum trust. Such applications will allow consumers' access to services and products without thinking how the industry generally works and how the information systems that support the automation of the sector function.

This ecosystem creates the basis for a publicprivate partnership in digitization of various economic sectors and provides an opportunity for many third-party developers: the producers of new devices, products, tools and digital services to join the process. Openness for participation, government support and a competitive environment will create the proper conditions for the number of available digital services to grow and for their quality to improve. At the same time, the state will be able to avoid expenses for mass development and the implementation of application services, creating an environment that encourages small and medium business participation, thus supporting Russian providers of services, gadgets and other devices.

While considering different ways to realize this ecosystem, we should take into account that a technology that can solve all industry problems simultaneously does not exist. The challenges of sectoral digital transformation are too monumental and complicated for one company. Therefore, we should not think about separate systems and services but discuss the possibility of using a platform that provides the opportunity for the collaboration of separate systems and organizations from both technological and commercial standpoints.

The economy of knowledge is the basis for all digital economic sectors (sub-sectors). The knowledge keeper in this economy should be a semantic core, the support and development of which is a vitally important and scientifically intensive activity for the digital economy. For example, in the banking sector, where semantic interoperability is important [16], Financial Industry Business Ontology (FIBO) is being implemented $^{8}$. A joint effort by the Object Management Group (OMG) and the Enterprise Data Management (EDM) Council, FIBO is an industry initiative to define financial industry terms, definitions and synonyms using semantic web principles such as RDF/ OWL and widely adopted OMG modeling standards such as UML, started in the end of 2015. FIBO is designed and developed according to regulatory requirements, e.g. the Basel Committee on Banking Supervision (BCBS) 239 compliance for effective risk data aggregation and risk reporting is a major driver for FIBO [17].

${ }^{8}$ https://www.edmcouncil.org/financialbusiness (accessed 19 September 2017) 
To reduce the costs of integration, increase the flexibility of IT solutions and to optimize banking IT architecture, the Banking Industry Architecture Network (BIAN) was created and is being developed by an international association of banks and suppliers of IT solutions 9 BIAN is a collaborative not-for-profit ecosystem formed from global leading banks, technology providers, consultants and academics. It can become a good example of a second approach where community members combine their industry expertise to create a revolutionary banking technology framework that standardizes and simplifies core banking architecture, which has typically been convoluted and outdated. Based on service-oriented architecture principles, the comprehensive model provides a future-proof solution for banks that fosters industry collaboration. BIAN plans to use FIBO, considering it to be a crucial, complementary initiative" ${ }^{10}$.

The current version (BIAN v.5) includes 7 business lines, 36 business domains, about 300 services in different domains, more than 700 business scenarios and about 2000 standard business operations in these services. Among the participants, there are 27 financial institutions (ABN AMRO Group, Credit Suisse, Societe Generale Group, Deutsche Bank, Unicredit Group, ING, Achmea, Rabobank, UBS, Banko Galicia and others) and 43 software producers (Temenos, Diasoft, Infosys, Sopra Banking Software, TCS Banks, IBM, SAP, Microsoft and others).

In healthcare, interoperability and standardization have been developing since the 1970s within the strategic healthcare initiative started in the USA. These initiatives have led to such significant projects as the Health Level Seven International (HL7) and the Unified Medical Language System (UMLS). HL7 was founded in 1987 to produce a standard for the exchange of data with hospital information systems.

Presently HL7 is not only a set of standards, but it is a not-for-profit, ANSI-accredited standards developing organization dedicated to providing a comprehensive framework and related standards for the exchange, integration, sharing, and retrieval of electronic health information that supports clinical practice and the management, delivery and evaluation of health services ${ }^{11}$.

The Unified Medical Language System (UMLS) integrates and distributes key terminology, classification and coding standards, and associated resources to promote the creation of more effective and interoperable biomedical information systems and services, including electronic health records. It is an example of a universal reference book of medical knowledge in the broadest sense possible, created with the use of the most effective methods made in computer knowledge processing. UMLS development started in 1986 at the National Library of Medicine, USA. Such terms as semantic representation and medical knowledge processing are used in UMLS ontologies describing all possible domains making up the medical knowledge universe which are created and constantly developed ${ }^{12}$.

UMLS has three tools which developers call Knowledge Sources:

Metathesaurus: Terms and codes from many vocabularies, including CPT®, ICD10-CM, LOINC ${ }^{\circledR}, \mathrm{MeSH}{ }^{\circledR}, \mathrm{RxNorm}$, and SNOMED CT ${ }^{\circledR}$;

$\diamond$ Semantic Network: Broad categories (semantic types) and their relationships (semantic relations);

$\diamond$ SPECIALIST Lexicon and Lexical Tools: Natural language processing tools.

Considering the international approaches

\footnotetext{
${ }^{9}$ https://bian.org/ (accessed 19 September 2017)

${ }^{10} \mathrm{http}: / /$ fibo2017.dataversity.net/sessionPop.cfm?confid=116\&proposalid=10193 (accessed 19 September 2017)

${ }^{11} \mathrm{http}: / /$ www.hl7.org/ (accessed 19 September 2017)

${ }^{12}$ https://www.nlm.nih.gov/research/umls/ (accessed 19 September 2017)
} 


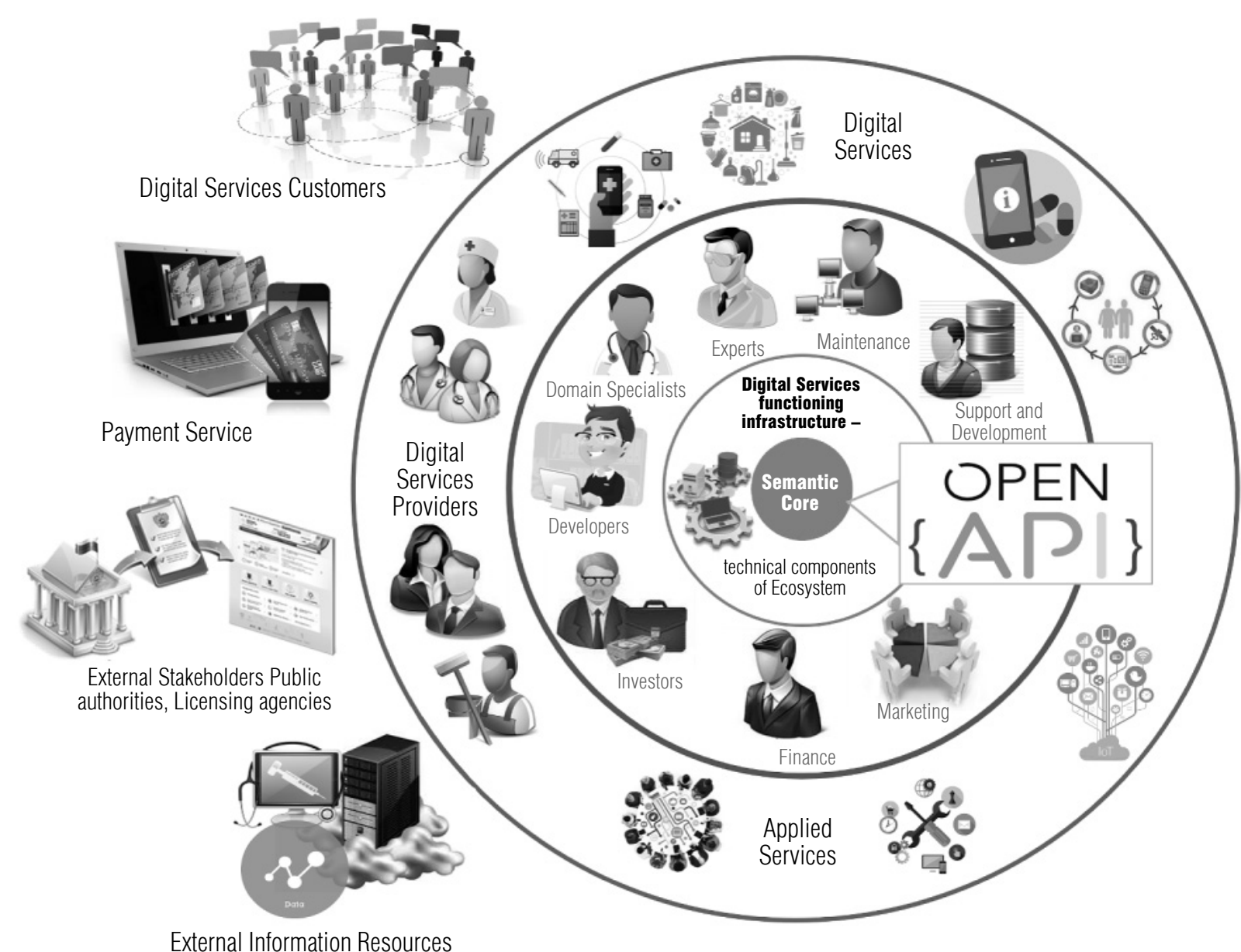

Fig. 1. Conceptual architecture for a digital economic sector ecosystem

to building digital economy platforms in the healthcare and financial sectors, the authors developed a conceptual architecture for a digital economic sector ecosystem.

\section{Conceptual architecture of a digital economic sector ecosystem}

We represent a conceptual architecture for the digital economic sector ecosystem (Figure 1) as a set of levels, interacting with each other in compliance with consistent rules:

1. Semantic core;

2. Digital services functioning infrastructure, which is the technical component of the ecosystem;

3. Digital services for customers and applied services for ecosystem participants, including visual interfaces and the application marketplace, as well as open tools for developers;

4. Personalized gadgets, wearables and IoT devices.

The basis for digital sector ecosystem creation and development can be an industry cluster formed as an independent entity by uniting leading enterprises interested in the promotion of the digital sector (for example, in healthcare it can be National scientific and medical centers), within state regulation, cluster policy realization and other measures of state support [18].

The core of the cluster should be a specially organized entity which will serve as a tool for 
the ecosystem's development, support and expansion.

1. For affiliated organizations, the cluster is a project office, center of competence, $R \& D$ center which carries out:

- preventive engineering and the approbation of new technologies;

- designing the transformation of existing procedures and business processes, embedding and integration in existing business processes;

- product testing on a platform that simulates digital sector business procedures for the embedding and integration of services;

- development of ecosystem technical components, including OpenAPI and infrastructure services;

- creation of a monitoring system to control the quality of industry digital services through all lifecycle phases.

2. For sector companies, institutions and structures, it is a center for digital transformation and the adaptation of services and products to a digital market, providing:

- digitization of existing processes and the adoption of best solutions within the digital sector;

- legitimization of existing mobile services, cooperation with other enterprises, organizations or institutions for the improvement of service quality;

- simplification of information security procedures.

3. For customers, it is an application access center, supporting:

- extended access mechanisms, concealing the complexity of procedures from clients, requiring no additional hardware facilities and simplifying the access of various customer categories to the services;

- publication of applications developed by ecosystem participants;

- implementation and integration of IoT devices and relevant applications for their everyday use.

4. For development companies, it is a platform for quality control and product expansion, a competence center and business accelerator, facilitating:

- the use of infrastructure applied services and tools for developers;

- the design of applications that can work with OpenAPI and other digital systems and services within the ecosystem;

- tests of applications, publishing and selling them via standard application marketplaces;

- the search for investors and the creation a primary reputation for start-ups;

- participation in the expert community for semantic core development and standardization of the requirements for applications and services.

\section{Conclusion}

Hence, for the successful transformation to a digital economy in key economic industries it is advisable to form a state regulation system for the digital sector (sub-sector) as well as:

$\checkmark$ to provide legitimization to digital services and, if necessary, digital device registration (which is essential in sectors that are highly regulated by public authorities, e.g. in healthcare, education, finance);

$\downarrow$ to develop a system of state support measures for the digital sector (including the creation of pilot projects, the development of PPPs, the formation of business incubators and stimulation of digital services implementation in industry enterprises;

$\downarrow$ to create and develop a digital sector ecosystem;

$\downarrow$ to conceptualize a methodology for the formation of a semantic core as a warehouse of complete and consistent knowledge of the subject area (glossaries, classifiers, thesauri, ontologies, models, standards, interaction schemes, 
including international schemes) and to create an expert community:

$\downarrow$ to provide the filing of the semantic core based on harmonized Russian and international reference books, classifiers, thesauri and ontologies for informational resources, sharing and standardization of interaction between providers and customers of digital services;

$\downarrow$ to develop an infrastructure for the functioning of digital services, and to ensure the use of information resources existing in the sector;

$\checkmark$ to create pilot digital services and test them using the tools of the functioning infrastructure, and then to provide their seamless integration with existing systems for subsequent digital transformation of business processes performed by sector enterprises;

$\checkmark$ to provide the transfer of innovative solutions to sector enterprises and support for domestic start-up companies.
Based on the approaches presented, the authors of this paper prepared detailed suggestions for the digital transformation in healthcare, the fundamental propositions of which were included in the "Digital Healthcare" section of the "Digital Economy" program draft worked out in accordance with "Assignment List for Realization of President's Message to the Federal Assembly" [19].

With the expansion of the adopted program for the "Digital Economy" [20] the implementation of the suggested sectoral strategy for digital transformation will create significant benefits through the rapid development of new, customer-oriented products and solutions, as well as high flexibility and adaptability to changing needs. The effectiveness of the strategy is largely determined by the creation of an ecosystem that provides favorable conditions enabling innovations in developing companies.

\section{References}

1. Schwab K. (2016) Chetvertaya promyshlennaya revolyutsiya [The fourth industrial revolution]. Moscow: Eksmo (in Russian).

2. Mitin V. (2017) Sem'opredeleniy tsifrovoy ekonomiki [Seven definitions of digital economy]. Available at: https://www.crn.ru/news/detail.php?ID=116780 (accessed 19 September 2017) (in Russian).

3. Akatkin Y., Yasinovskaya E., Drozhzhinov V., Konyavskiy V. (2016) Towards the digital government in Russia: Integrative approach. Proceedings of International Conference on Electronic Governance and Open Society: Challenges in Eurasia (EGOSE'16). St. Petersburg, Russia, 22-23 November 2016. N.Y.: ACM New York, pp. 41-48.

4. Markovitch S., Willmott P. (2014) Accelerating the digitization of business processes. Available at: http:// www.mckinsey.com/business-functions/digital-mckinsey/our-insights/accelerating-the-digitization-ofbusiness-processes (accessed 19 September 2017).

5. Stogney A., Sedov D. (2016) Banki dlya gikov: eksperty nazvali liderov finansovykh innovatsiy [Banks for geeks: experts listed the leaders of finance innovations]. Available at: http://money.rbc.ru/ news/57bb7ffe9a7947340fa28c1f (accessed 19 September 2017) (in Russian).

6. Pertlweiser M. (2016). For the banking of the future - Deutsche Bank's digital factory. Available at: https://www.db.com/newsroom_news/16_09_29_Digital_Factory_Opening_final_Englisch.pdf (accessed 19 September 2017).

7. Deutsche Bank (2016) Deutsche Bank opens its data store to external software developers (October 2016). Available at: https://www.db.com/newsroom_news/2016/medien/deutsche-bank-opens-its-data-storeto-external-software-developers-en-11735.htm (accessed 19 September 2017).

8. Kantyshev P. (2016) «Sbertekh» stal pervym po golovam [Sbertech became a headhunting leader]. Vedomosti, no. 4173 (3 October 2016) (in Russian).

9. TAdviser (2016) «Sberbank rasskazal na TAdviser SummIT o revolyutsionnoy transformatsii IT-sistem [Sberbank told on TAdviser SummIT about revolutionary transformation of IT systems]. Available at: http://tadviser.ru/a/318028 (accessed 19 September 2017) (in Russian). 
10. Karpov O., Akatkin Y., Konyavsky V., Mikerin D. (2016) Tsifrovoe zdravookhranenie v tsifrovom obshchestve [Digital healthcare in digital society]. Moscow: Delovoy Express (in Russian).

11. Accenture (2016) Accenture digital health vision 2016. Available at: https://www.accenture.com/us-en/ insight-healthcare-technology-vision-2016 (accessed 19 September 2017).

12. GOV.UK (2017) Personalised health and care 2020. Available at: https://www.gov.uk/government/ publications/personalised-health-and-care-2020 (accessed 19 September 2017).

13. Oxford Economics (2011) The new digital economy. How it will transform business. Available at: http:// www.pwc.com/mt/en/publications/assets/the-new-digital-economy.pdf (accessed 19 September 2017).

14. European Parliamentary Research Service Blog (2013) $21 \%$ GDP productivity growth - Why the digital economy is important! Available at: https://epthinktank.eu/2013/11/11/21-gdp-productivity-growthwhy-the-digital-economy-is-important/ (accessed 19 September 2017).

15. Betancourt R.R. (2017) Distribution services and the digital economy: Implications for GDP measurement, productivity and household welfare. Available at: http://economics.fiu.edu/events/2017/seminar-rogerbetancourt-2/betancourt2017.pdf (accessed 19 September 2017).

16. Reingold L.A., Volkov A.I., Kopaygorodsky A.N., Pustozerov E.Y. (2016) Semanticheskaya interoperabel'nost' $\mathrm{v}$ reshenii finansovykh zadach i sposoby ee izmereniya [Semantic interoperability in solving financial problems and ways of measuring it]. Applied Informatics, vol. 11, no. 4 (64), pp. 115-134 (in Russian).

17. Zaino J. (2016) Banking on FIBO: Financial institutions turn to semantic standard. DATAVERSITY (October 2016). Available at: http://www.dataversity.net/banking-fibo-financial-institutions-turn-standard-value-compliance/ (accessed 19 September 2017).

18. Skvortsov E.N., Guskova N.D. (2016) Analiz organizatsionnykh struktur sistem upravleniya innovatsionnymi promyshlennymi klasterami $v$ Rossii [Analysis of organizational structures of management systems for innovative industrial clusters in Russia]. Economics Portal (14 June 2016). Available at: http://institutiones.com/innovations/2806-analiz-organizacionnyx-struktur.html (accessed 19 September 2017) (in Russian).

19. The President of Russia (2016) Perechen' porucheniy po realizatsii Poslaniya Prezidenta Federal'nomu Sobraniyu [Assignment list for realization of the President's Message to the Federal Assembly]. Available at: http://kremlin.ru/acts/assignments/orders/53425 (accessed 19 September 2017) (in Russian).

20. The Government of the Russian Federation (2017) Programma «Tsifrovaya ekonomika Rossiyskoy Federatsii» [The Digital Economy of the Russian Federation Program]. Approved by the Government of the Russian Federation in its resolution No. 1632-r, 28 July 2017. Available at: http://ac.gov.ru/files/ content/14091/1632-r-pdf.pdf (accessed 19 September 2017) (in Russian). 